\title{
Immunohistochemical localization of selected pro-inflammatory factors in uterine myomas and myometrium in women of various ages
}

\author{
Andrzej Plewka ${ }^{1}$, Pawel Madej ${ }^{2}$, Danuta Plewka ${ }^{3}$, Anna Kowalczyk ${ }^{4}$, \\ Adam Miskiewicz ${ }^{1}$, Piotr Wittek ${ }^{1}$, Tomasz Leks ${ }^{2}$, Rafal Bilski ${ }^{2}$ \\ ${ }^{1}$ Department of Proteomics, Medical University of Silesia, Sosnowiec, Poland \\ ${ }^{2}$ Chair and Department of Gynecological Endocrinology, Medical University of Silesia, \\ Katowice, Poland \\ ${ }^{3}$ Department of Histology and Embryology, Medical University of Silesia, Katowice, Poland \\ ${ }^{4}$ Department of Human Histology and Embryology, University of Warmia and Masuria, \\ Olsztyn, Poland
}

\begin{abstract}
Uterine myomas represent one of the most frequently manifested benign tumors in women. They originate from smooth muscle cells of myometrium or its blood vessels. Many studies suggest that inflammation and pro-inflammatory factors may play a role in the carcinogenesis with an involvement of the transcription factor NF- $\kappa \mathrm{B}$ which activity can be controlled by various environmental factors, including many cytokines. The aim of the study was to investigate the expression of NF-B, interleukin- $1 \beta$ (IL- $1 \beta$ ), tumor necrosis factor a (TNF- $\alpha$ ), cyclooxygenase $2(\mathrm{COX}-2)$ and inducible nitric oxide synthase (iNOS) in myometrium and uterine myomas of women of various age. The expression of NF- $\kappa \mathrm{B}$, selected cytokines and enzymes was estimated in women of reproductive or perimenopausal age by semiquantitative immunohistochemistry. The expression of the examined proteins was higher in myomas than in control myometrium and was dependent on the size of myomas and the age of women. However, the expression of the cytoplasmic NF- $\kappa$ B observed in uterine myomas was independent on the size of myomas and no significant differences were observed in the number of stained nuclei between control and myoma groups. Thus, the expression of proinflammatory factors in myomas was not accompanied by the nuclear activation of NF- $\kappa \mathrm{B}$ p 65 . The results of our study indicate that the examined factors may be involved in the pathogenesis of benign tumors and not only malignant diseases. (Folia Histochemica et Cytobiologica 2013, Vol. 51, No. 1, 73-83)
\end{abstract}

Key words: women, uterine myomas, myometrium, NF- $\kappa \mathrm{B}, \mathrm{IL}-1 \beta$, TNF- $\alpha$, COX-2, iNOS, immunohistochemistry, age

\section{Introduction}

Uterine myomas are the most common benign tumors in women, but in spite of this, the mechanisms and factors that control their formation and development are poorly understood. Many studies showed the par-

Correspondence address: A. Plewka

Department of Proteomics, Medical University of Silesia,

Ostrogórska St. 30, 41-200 Sosnowiec, Poland;

tel.: + 483236414 30; fax.: + 483236414 40;

e-mail: aplewka@sum.edu.pl ticipation of pro-inflammatory factors in the pathogenesis of various types of cancer [1-4] through their effects on cell growth and differentiation, apoptosis, angiogenesis, and tissue remodeling [1, 2, 4, 5], i.e. events that are central to tumor growth.

Nuclear factor $\kappa \mathrm{B}(\mathrm{NF}-\kappa \mathrm{B})$ represents an important transcription factor which participates in several cellular reactions to environmental changes. The activity of NF- $\kappa \mathrm{B}$ is an important element in the specific and non-specific mechanism of immune control over inflammatory processes and is tightly controlled by several regulatory proteins (e.g. tumor necrosis 
factor $\alpha$ [TNF- $\alpha]$ or interleukin-1). The genes regulated by NF- $\kappa \mathrm{B}$ involve those coding for cytokines, including interleukin-1 $\beta$ (IL-1 $\beta$ ), interleukin-6 (IL-6) or TNF- $\alpha$, and genes coding for anti-apoptotic proteins or proteins which control cell proliferation [4, $6-8]$. They also include genes coding for cyclooxygenase 2 (COX-2) and inducible nitric oxide synthase (iNOS) [9-12]. Cyclooxygenases form a group of enzymes involved in many inflammatory processes. Two forms of the enzyme include the constitutive form, COX-1 and the inducible form, COX-2. Normal uterine smooth muscle cells contain both forms of the enzyme. COX-2, which converts arachidonic acid into prostaglandin $\mathrm{H}_{2}$ (precursor of all prostaglandins [PGs] and thromboxanes), represents a mitogen-induced form of cyclooxygenase, manifesting expression in response to various inflammatory stimuli including IL- $1 \beta$ and TNF- $\alpha$. In myometrium and endometrium estrogens stimulate COX-2 to synthesize $\mathrm{PGE}_{2}$ [13]. The $\mathrm{PGE}_{2}$ is associated with proinflammatory mechanisms and could enhance the function of $\mathrm{NFkB}$, whereas the $\mathrm{PGA}_{1} \mathrm{PGA}_{2}$ and $\mathrm{PGJ}_{2}$ are associated with suppression of inflammation and are able to inhibit NF-kB activation [14-16]. Inducible NOS was identified in several cell types, including macrophages and smooth muscle cells [17]. Nitric oxide, synthesized by iNOS, is a mediator involved in various cellular processes. Expression of iNOS was found also in tumors of female reproductive tract [18-20].

IL- $1 \beta$ and TNF- $\alpha$ stimulate TRAF6 (tumor necrosis factor receptor associated factor 6) [21], the effect of which directly stimulates the expression of NF- $\kappa$ B [22]. IL- $1 \beta$ and TNF- $\alpha$ increase the level of iNOS mRNA by transcriptional activation [23]. These cytokines also increase the expression of COX-2, the activity of which is controlled by NOS, particularly by its inducible form [24]. Moreover, high level of estrogens activates iNOS $[25,26]$, which may significantly affect physiology of myometrium. An increased release of estrogens as a result of induction of aromatase [27] results in increased risk of myoma development due to a direct stimulation of proliferation [28] and increased activity of cyclooxygenase-2 [29].

To our knowledge, the localization and cellular expression of NF- $\kappa \mathrm{B}$ and iNOS in uterine myomas has not yet been examined, thus the aim of the presented study was to investigate by immunocytochemistry the expression of NF- $\kappa \mathrm{B}, \mathrm{IL}-1 \beta$, TNF- $\alpha$, COX-2, iNOS in uterine myomas in women of reproductive or perimenopausal age.

\section{Material and methods}

Human material. Recruitment of patients, clinical studies and hormonal tests were conducted in the Chair and De- partment of Gynecological Endocrinology, Medical University of Silesia in Katowice, Poland, while enzymatic and protein studies were executed in the Department of Proteomics.

The studies were conducted on 40 patients with myomas at the reproductive age (below 45th year of age, FSH $<30 \mathrm{mIU} / \mathrm{mL}$; samples collected during the follicular phase of menstrual cycle) and 40 patients with myomas at the perimenopausal age ( $45-55$ years, FSH $>30 \mathrm{mIU} / \mathrm{mL}$ ). Inclusion criteria involved myoma detected by USG, qualification of the patient to hysterectomy, informed consent to the planned studies. The exclusion criteria included: therapy with any drugs, including hormonal drugs for at least 3 months before inclusion to the studies, neoplastic disease, endometrial hypertrophy, metabolic and systemic disturbances, and nicotinism. In these studies we used only material from uteruses with one large myoma or one large and few small myomas.

Myometrial samples (control groups) were taken from 10 women $(<40$ years old) undergoing hysterectomies for ovary tumors and 10 older women ( $>52$ years old) undergoing hysterectomies for uterine prolapse.

The investigative procedures were approved by the local Medical Bioethical Commission.

Characteristics of studied groups. Group 1 denoted as "control group of reproductive age women": myometrium of young women, in whom hysterectomy was performed for reasons other than uterine leiomyomas $(\mathrm{n}=10)$. Group 2 denoted as "small myomas of reproductive age women": leiomyomas of $<3 \mathrm{~cm}$ in diameter $(\mathrm{n}=20)$. Group $3 \mathrm{de}-$ noted as "large myomas of reproductive age women": leiomyomas of $>5 \mathrm{~cm}$ in diameter $(\mathrm{n}=20)$. Group 4 denoted as "control group of perimenopausal age women: myometrium of perimenopausal age women, in whom hysterectomy was performed for reasons different than uterine leiomyomas $(n=10)$. Group 5 denoted as "small myomas of perimenopausal age women": leiomyomas of $<3 \mathrm{~cm}$ in diameter $(n=20)$. Group 6 denoted as "large myomas of perimenopausal age women": leiomyomas of $>5 \mathrm{~cm}$ in diameter $(n=20)$.

Immunohistochemical studies. Tissue samples were fixed in $10 \%(\mathrm{v} / \mathrm{v})$ solution of buffered formalin for $24 \mathrm{~h}$ at $4^{\circ} \mathrm{C}$, and then dehydrated, cleared in xylenes and embedded in paraffin. Paraffin sections $(5 \mu \mathrm{m})$ were mounted on silanecoated slides, de-waxed, and rehydrated. The sections were treated with $10 \mathrm{mM}$ citrate buffer, $\mathrm{pH} 6.0$ in water bath $\left(30 \mathrm{~min}\right.$ at $95^{\circ} \mathrm{C}$ ) for antigen retrieval, then treated with $1.5 \%$ (v/v) $\mathrm{H}_{2} \mathrm{O}_{2}$ in methanol for 10 min for quenching of endogenous peroxidase activity, and equilibrated in $10 \mathrm{mM}$ PBS$0.05 \% \mathrm{v} / \mathrm{v}$ Tween $20 \mathrm{pH}$ 7.5. Nonspecific binding was reduced by incubation in 1\% BSA for $60 \mathrm{~min}$. After this the slides were incubated with rabbit anti-NF- $\kappa$ B p65 (sc-109, Santa Cruz Biotech, Santa Cruz, CA USA), anti-IL-1 $\beta$ (ab2105, Abcam, Cambridge, MA, USA), anti-iNOS 
Table 1. Quantitative evaluation of protein expression by immunohistochemical staining in myometrium and myomas of reproductive and perimenopausal age women

\begin{tabular}{|l|c|c|c|c|c|c|}
\hline \multirow{2}{*}{ Protein } & \multicolumn{3}{|c|}{ Reproductive age } & \multicolumn{3}{c|}{ Perimenopausal age } \\
\cline { 2 - 7 } & Control group & Small myomas & Large myomas & Control group & Small myomas & Large myomas \\
\hline NF- $\kappa$ B & $57.1 \pm 10.7$ & $120.6 \pm 13.9^{\text {a }}$ & $119.5 \pm 8.8^{\text {b }}$ & $59.0 \pm 9.0$ & $87.0 \pm 10.2^{\text {a.e }}$ & $82.0 \pm 11.3^{\text {b.f }}$ \\
\hline IL-1 & $33.2 \pm 3.9$ & $183.4 \pm 9.1^{\text {a }}$ & $210.6 \pm 12.2^{\text {b.c }}$ & $38.4 \pm 4.7$ & $195.3 \pm 12.4^{\text {a }}$ & $175.1 \pm 11.1^{\text {b.d.f }}$ \\
\hline TNF- $\alpha$ & $67.3 \pm 7.9$ & $121.5 \pm 8.3^{\text {a }}$ & $133.3 \pm 10.2^{\text {b }}$ & $72.2 \pm 7.0$ & $140.9 \pm 9.0^{\text {a.e }}$ & $110.2^{\text {a }} \pm 8.9^{\text {b.d.f }}$ \\
\hline COX-2 & $51.8 \pm 11.7$ & $110.4 \pm 13.1^{\text {a }}$ & $116.5 \pm 11.5^{\text {b }}$ & $56.9 \pm 9.5$ & $122.9 \pm 14.1^{\text {a }}$ & $85.5 \pm 10.5^{\text {b.d.f }}$ \\
\hline iNOS & $63.4 \pm 9.4$ & $115.7 \pm 6.2^{\text {a }}$ & $135.3 \pm 8.0^{\text {b.c }}$ & $67.7 \pm 10.6$ & $130.7 \pm 9.2^{\text {a.e }}$ & $124.6^{\text {byyyyy}} \pm 6.3^{\text {b }}$ \\
\hline
\end{tabular}

The staining intensity was measured as described in methods. Data show an average optical density \pm SD (see material and methods). Statistical

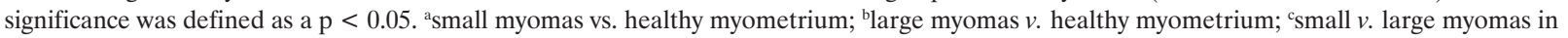
reproductive age women; ${ }^{\mathrm{d}} \mathrm{small} v$. large myomas in perimenopausal age women; ${ }^{\mathrm{e}} \mathrm{small}$ myomas in reproductive age women $v$. small myomas in perimenopausal age women; flarge myomas in reproductive age women $v$. large myomas in perimenopausal age women

(ab15323, Abcam) and anti-TNF- $\alpha$ (ab6671, Abcam) polyclonal antibodies or mouse anti-COX-2 monoclonal antibody (sc-58344, Santa Cruz) in a humidified chamber for $22 \mathrm{~h}$ at $4^{\circ} \mathrm{C}$. After washing in PBS-Tween 20 the sections were incubated with biotinylated goat anti-rabbit or horse anti-mouse immunoglobulins (Vector Laboratories, Burlingame, VA, USA) for $30 \mathrm{~min}$, and next with avidin-biotinylated peroxidase complex (Vector) for $30 \mathrm{~min}$. The bound antibodies were visualised with diaminobenzidine (DAB) and $\mathrm{H}_{2} \mathrm{O}_{2}$ in PBS, pH 7.5 according to supplier's instructions (Vector). Finally, the tissues were stained with Gill's hematoxilin, dehydrated, and cover-slipped. Negative controls were performed by substituting the primary antibodies with rabbit $\mathrm{IgG}$ or mouse $\mathrm{IgG}$ respectively.

Archives. Photographic documentation was prepared using a light photomicroscope. In order to accentuate the immune reactions, every reaction was documented by 10 photographs under $200 \times$ magnification $(20 \times$ objective and $10 \times$ ocular $)$ using a digital camera-equipped Nikon microscope.

Optical density measurements. In each positively stained cell, the intensity of staining was measured as the optical density of the reaction product, with the program KS 300 VIDAS video image analyzer served by IBAS 2.5 system and a digital camera. For each analyzed area, $173 \times 130 \mu \mathrm{m}$ average optical density was calculated [30]. Three sections for every studied protein and every patient were analyzed. In each section ten fields were examined. Finally, the arithmetic mean and standard deviation were calculated.

Statistical analysis. Normal distribution of the data was confirmed by the Kolmogorov-Smirnov test. Results are presented as a mean \pm standard deviation. The Student's $t$-test was performed. A $\mathrm{P}$ value $<0.05$ was considered to be statistically significant.

\section{Results}

\section{Expression of the nuclear transcription factor $\boldsymbol{\kappa B}$ $(\mathrm{NF}-\kappa \mathrm{B})$}

$\mathrm{NF}-\kappa \mathrm{B}$ showed both nuclear and cytoplasmic staining. No significant differences were observed in the number of stained nuclei between control groups and myoma groups (small and large myomas) in women of different age (data not shown).

\section{Cytoplasmic localization and its analysis}

Reproductive age. Cytoplasmic expression of NF- $\kappa \mathrm{B}$ was about $100 \%$ higher in small and large myomas of reproductive age women than in the control (Table 1 , Figure 1).

Perimenopausal age. Cytoplasmic NF- $\kappa \mathrm{B}$ expression in small myomas was increased to almost $150 \%$ of the control level, and in large myomas to $140 \%$ of the control level (Table 1, Figure 1).

Effect of age. Cytoplasmic NF- $\kappa \mathrm{B}$ expression was similar in both control groups (Table 1). In perimenopausal age women the expression of NF- $\kappa \mathrm{B}$ was lower in both studied myoma groups as compared to myomas of young women.

\section{Interleukin-1 $\beta$ (IL-1 $\beta$ )}

\section{Reproductive age}

Expression of IL- $1 \beta$ in young women with small myomas was clearly higher than in the control and reached $550 \%$ of the control level (Table 1, Figure 2). IL- $1 \beta$ expression in large myomas amounted to $635 \%$ of the control level. Expression of the interleu- 

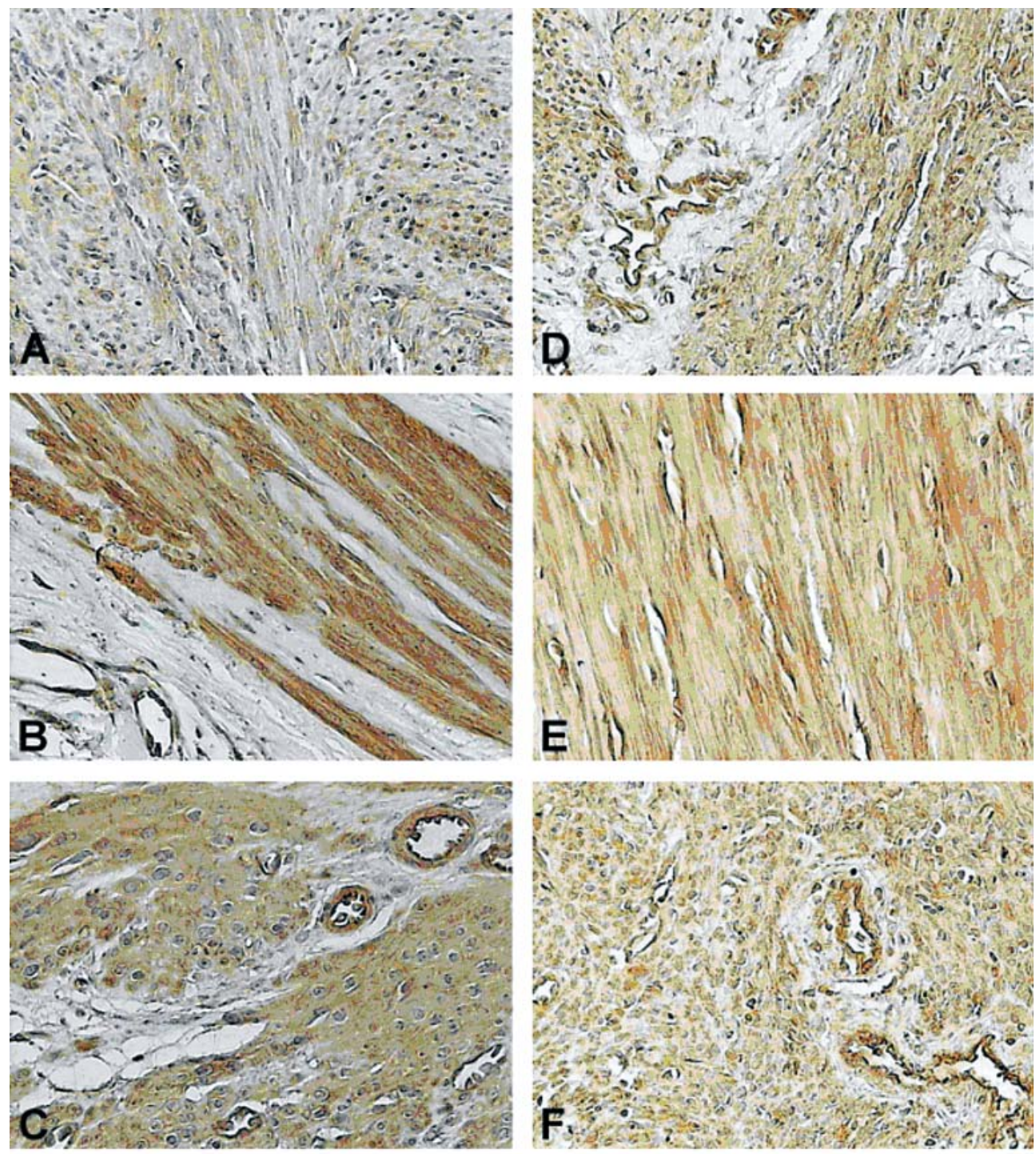

Figure 1. NF- $\kappa$ B presence in uteri from reproductive (A-C) and perimenopausal age women (D-F). A and D - myometrium of control groups, B and E - small myomas, $\mathrm{C}$ and $\mathrm{F}$ - large myomas. NF- $\kappa \mathrm{B}$ was detected by IHC as described in Methods. Total magnification $200 \times$

kin in large myomas in women of reproductive age was higher than in small myomas.

\section{Perimenopausal age}

In women of perimenopausal age IL- $1 \beta$ expression in small myomas increased to $510 \%$, and in large myomas to $455 \%$ of the control level (Table 1, Figure 2). In large myomas expression of IL- $1 \beta$ was lower than that in small myomas.

\section{Effect of age}

Comparison of IL- $1 \beta$ expression in control groups demonstrated that it was comparable in young and perimenopausal women (Table 1, Figure 2). Similarly, comparison of small myomas in women of the two studied age groups revealed no differences. In large myomas the expression of IL- $1 \beta$ at the perimenopausal age was lower and amounted to $80 \%$ of the expression seen in young women.

\section{Tumor necrosis factor- $\alpha$ (TNF- $\alpha)$}

Reproductive age

In young women the expression of TNF- $\alpha$ in small myomas was higher than in control myometrium and amounted to about $180 \%$. TNF- $\alpha$ expression in large myomas reached $200 \%$ of the control level (Table 1 , Figure 3). 

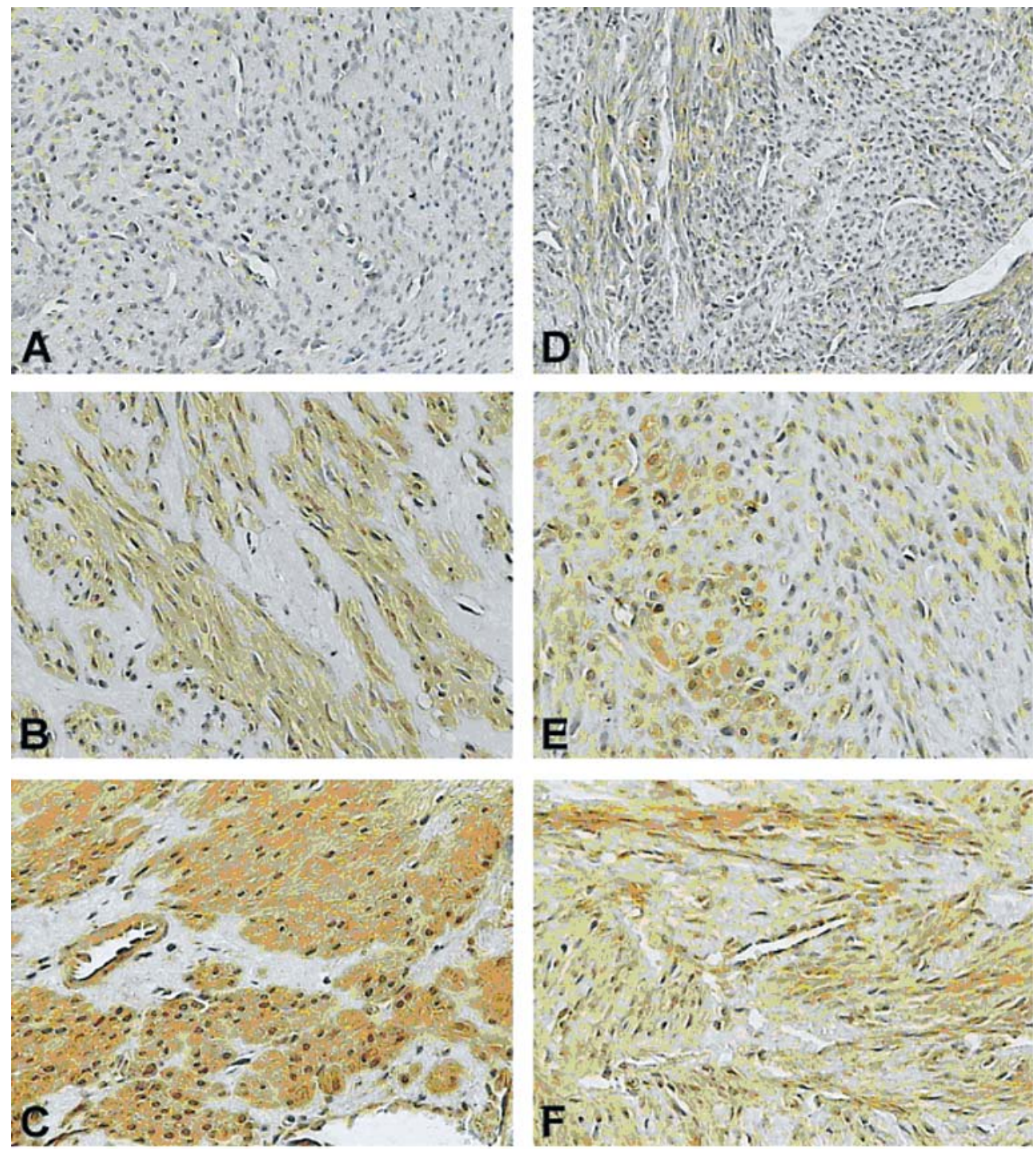

Figure 2. IL-1b presence in uteri from reproductive (A-C) and perimenopausal age women (D-F). A and D - myometrium of control groups, B and E - small myomas, C and F - large myomas. IL-1b was detected by IHC as described in Methods. $200 \times$

Perimenopausal age

The expression of TNF- $\alpha$ increased in women of perimenopausal age, in small myomas, reaching the level corresponding to $195 \%$ of the control value (Table 1 , Figure 3). The expression of TNF- $\alpha$ in large myomas was higher than in the control, reaching $155 \%$.In uterine myomas of women at perimenopausal age the expression of the cytokine was slightly lower in large than in small myomas, reaching $80 \%$ of the level in the latter.

\section{Effect of age}

The expression of TNF- $\alpha$ was found to be similar in young women and in women at perimenopausal age (Table 1, Figure 3). In small myomas, in young wom- en the expression of TNF- $\alpha$ reached $90 \%$ of the value disclosed in the older women. The expression of TNF- $\alpha$ in large myomas of women at perimenopausal age was noted to be lower, amounting to $75 \%$ of the value detected in young women.

\section{Cyclooxygenase-2 (COX-2)}

Reproductive age

COX-2 expression in small myomas of young women was increased to $215 \%$ of the control value (Table 1 , Figure 4 ), and in large myomas to $225 \%$ of the control value. In large myomas COX-2 expression was similar to the one found in small myomas. 

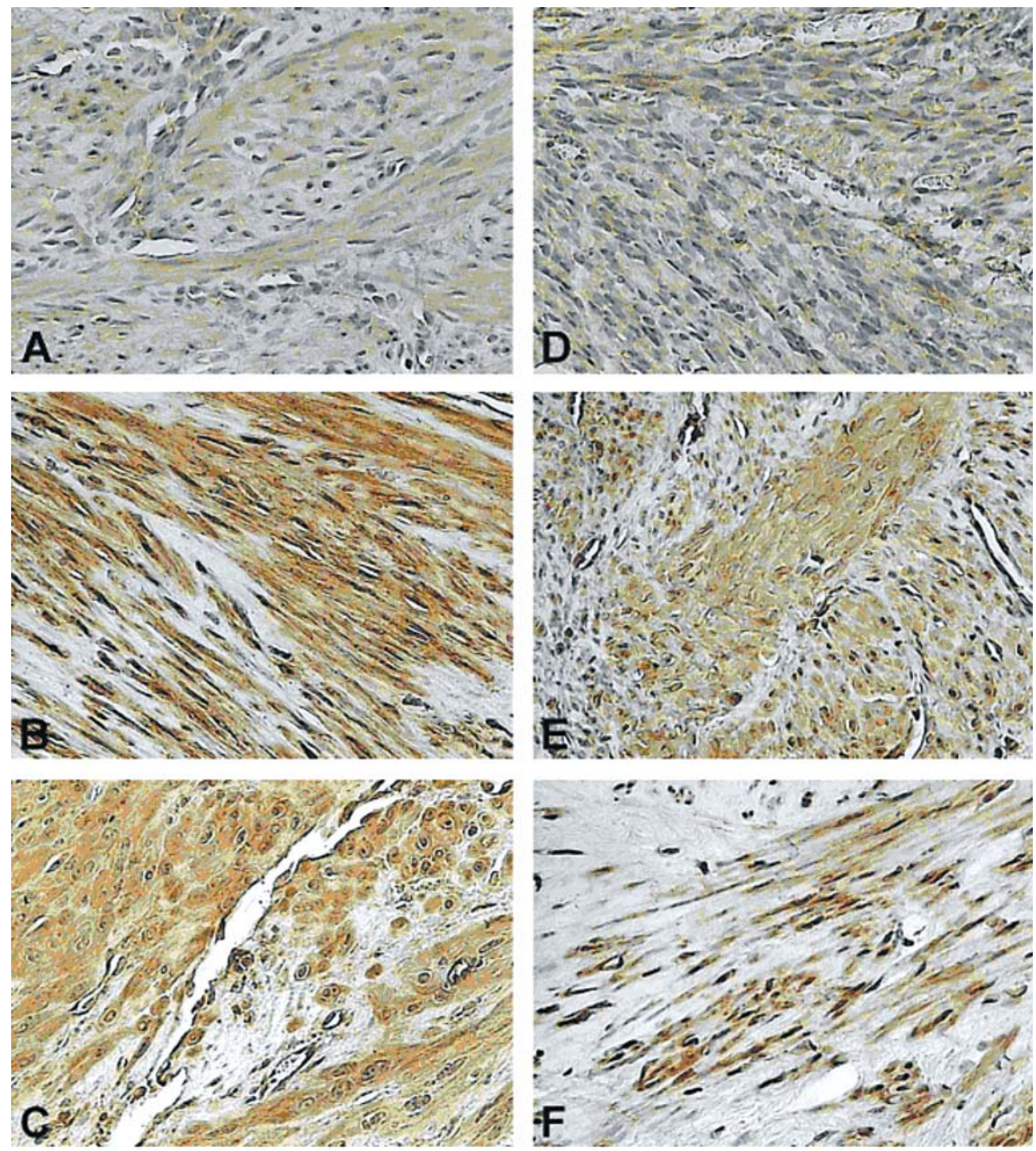

Figure 3. TNF- $\alpha$ presence in uteri from reproductive (A-C) and perimenopausal age women (D-F). A and D - myometrium of control groups, B and E - small myomas, $\mathrm{C}$ and $\mathrm{F}$ - large myomas. TNF- $\alpha$ was detected by IHC as described in Methods. $200 \times$

Perimenopausal age

COX-2 expression increased in small myomas to the level of almost $215 \%$ of the control value (Table 1 , Figure 4). In large myomas the expression of COX-2 was higher than in the control, reaching $150 \%$ of the control value.

\section{Effect of age}

Expression of the enzyme in control samples was similar in both studied age groups (Table 1, Figure 4). A similar situation was detected upon quantitative evaluation of the enzyme expression in small myomas in women of the two age groups. In large myomas the level of COX-2 expression in women of perimenopausal age was lower and corresponded to $65 \%$ of the level detected in the younger women.

\section{Inducible nitric oxide synthase (iNOS)}

Reproductive age. In young women iNOS expression increased in both small and large uterine myomas, reaching $185 \%$ and $215 \%$ of the control level, respectively (Table 1, Figure 5). In large myomas the expression of iNOS was higher than in small myomas and it reached almost $120 \%$ of the enzyme expression detected in small myomas. 

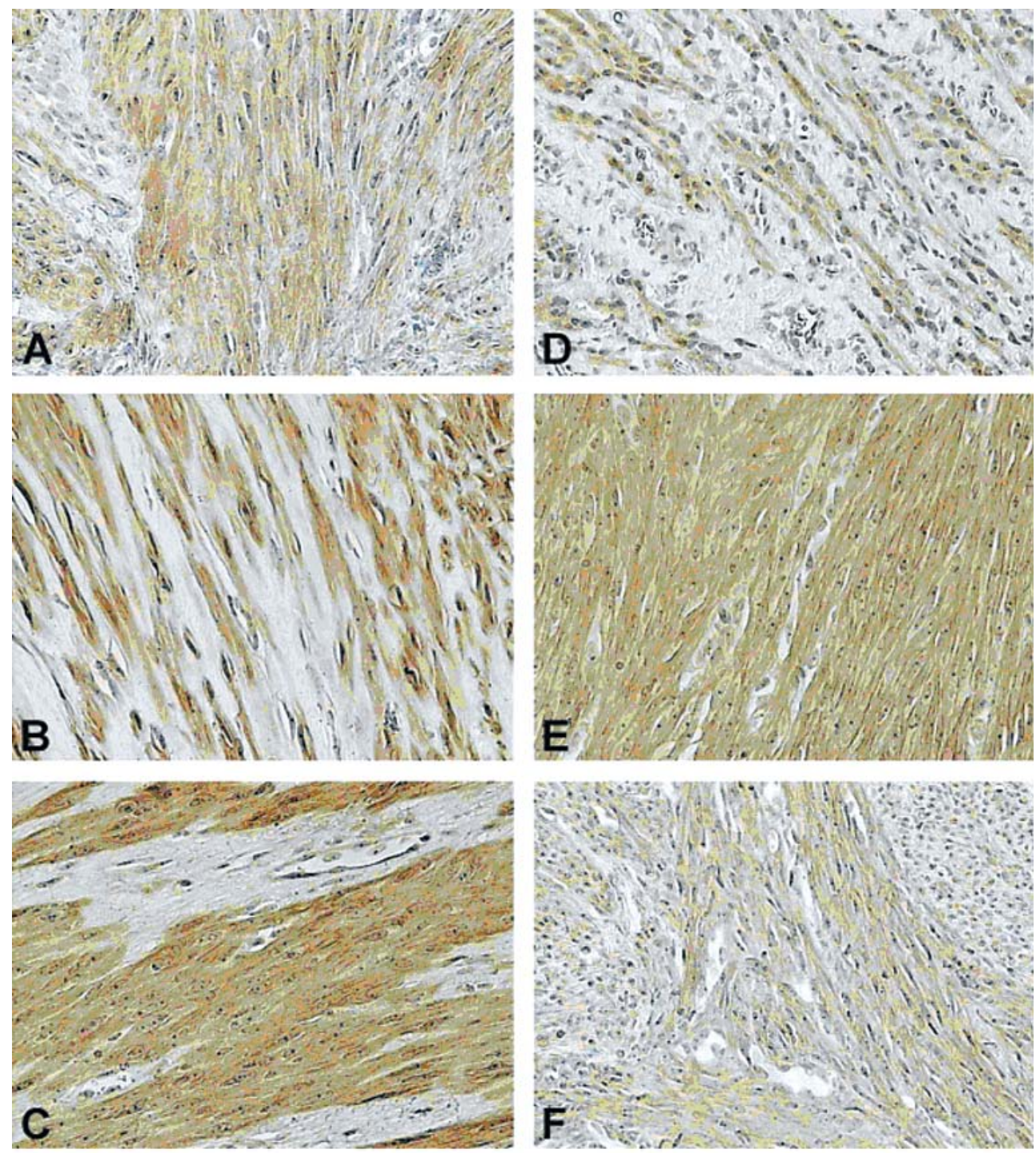

Figure 4. COX-2 presence in uteri from reproductive (A-C) and perimenopausal age women (D-F). A and D - myometrium of control groups, B and E - small myomas, C and F — large myomas. COX-2 was detected by IHC as described in Methods. $200 \times$

Perimenopausal age

iNOS expression in perimenopausal women increased in small myomas to the level corresponding to $190 \%$ of the control level (Table 1, Figure 5). In large myomas, as compared to the control, the expression was higher, amounting to $185 \%$ of the control.

\section{Effect of age}

iNOS expression in young and older women was similar (Table 1, Figure 5). In small myomas of women at perimenopausal age the expression of iNOS was higher $(12 \%)$ than in small myomas of young women. iNOS expression in large myomas of perimenopausal women was the same as that in young women.

\section{Discussion}

Pro-inflammatory factors and their regulators are multifunctional agents and it has been shown that they can control various processes associated with tumorigenesis [1-4]. IL-1 $\beta$ mRNA expression was identified for example in cells of melanoma, colon adenocarcinoma or non-small-cell lung cancer. It was found that this pluripotent cytokine promotes angiogenesis, tumor growth and metastasis [2]. Our studies revealed the expression of IL- $1 \beta$ in myometrium and uterine myomas of women of various age, whereas several times higher expression was observed in myomas. IL-1 may affect the growth of myomas cells, as 

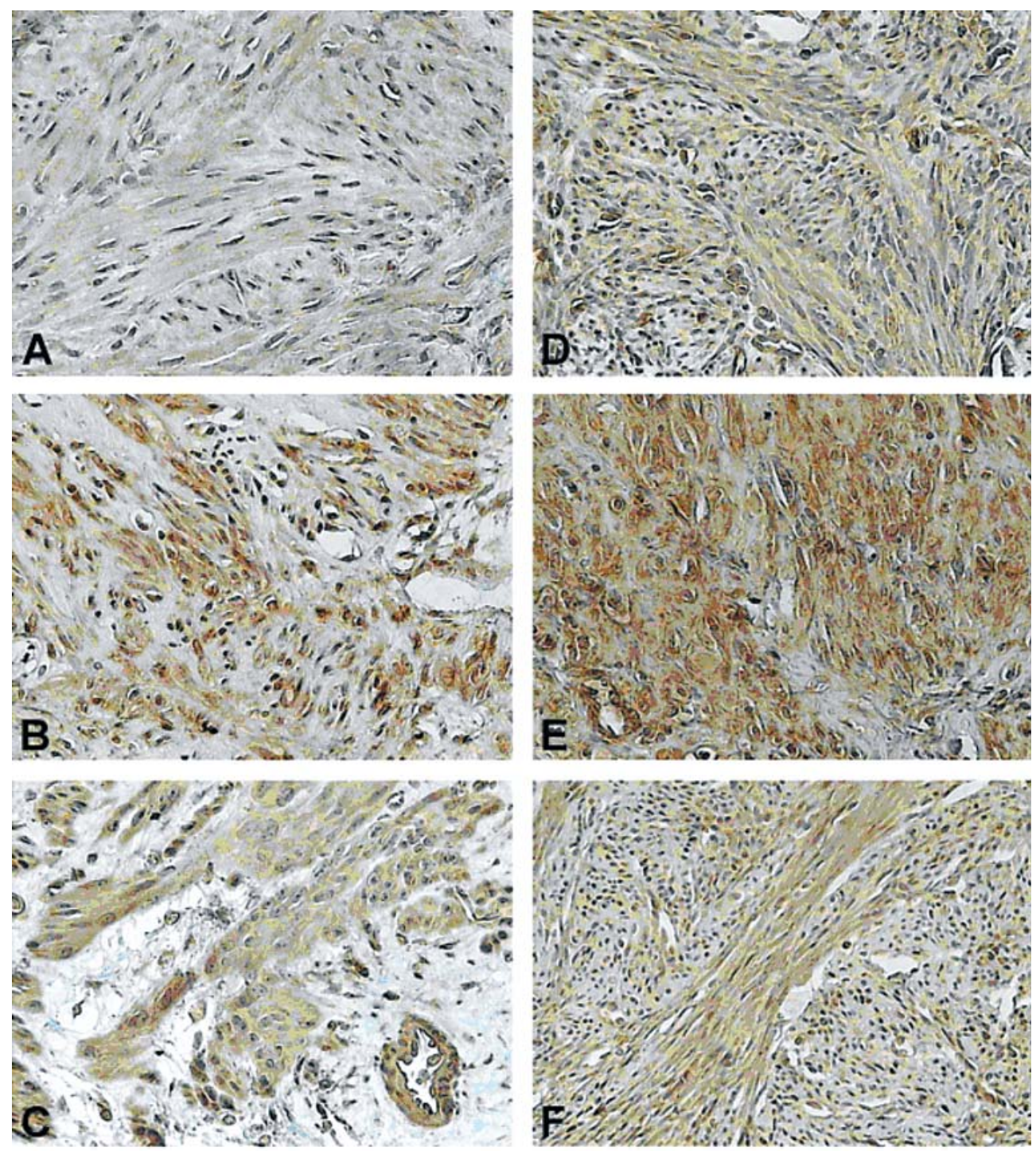

Figure 5. iNOS presence in uteri from reproductive (A-C) and perimenopausal age women (D-F). A and D - myometrium of control groups, B and E - small myomas, C and F — large myomas. iNOS was detected by IHC as described in Methods. $200 \times$

it was demonstrated in the case of vascular smooth muscle cells [31] or airway smooth muscle cells [32]. $\mathrm{TNF}-\alpha$ is another cytokine with dual role in cancer biology. This multifunctional cytokine plays a key role in apoptosis and cell survival as well as inflammation and immunity [33]. It can destroy blood vessels, but also induce several angiogenic factors [1]. TNF- $\alpha$ is mainly produced by activated macrophages, $\mathrm{T}$ lymphocytes, and natural killer cells, but lower expression was also observed in other cell types, including fibroblasts, smooth muscle cells, and tumor cells. TNF- $\alpha$ mRNA and protein were detected in malignant and/or stromal cells in human ovarian, breast, prostate, bladder and colorectal cancer, lymphomas and leukemia's, often in association with IL-1 $[1,33]$.
In our investigations immunoreactivity of TNF- $\alpha$ was significantly higher in myoma cells than in cells of control myometrium. These results are consistent with studies of Kurachi et al. [34] who showed that the expression of TNF- $\alpha$ in leiomyoma cells was higher than that in the normal myometrial cells and could be down-regulated by progesterone. Activity of IL- $1 \beta$ and TNF- $\alpha$ is particularly important since, on the one hand, they may directly affect the level of inducible cyclooxygenase $[16,35]$ and, on the other, they may indirectly, through TRAF proteins, stimulate activation of the NF- $\kappa$ B transcription factor [21]. We found that the expression profile of COX-2 was similar to the one of TNF- $\alpha$. Higher imunnoreactivity of COX-2 was observed in myoma tissue than the control myometri- 
um. The overexpression of this enzyme may be related to its function in the process of tumorigenesis. It was found that COX-2 prevented apoptosis and was associated with inflammation, cell growth and differentiation [5]. Prostaglandins produced via COX-2 activation, including prostaglandin E2 (PGE2), are believed to be the major contributors to cell proliferation [36], and PGE2 has been regarded as a primary COX-2 product in smooth muscle cells [37]. Transfection of rat intestinal epithelial cells with COX-2 gene caused inhibition of apoptosis accompanied by increased spontaneous output of $\mathrm{PGE}_{2}$ and increased levels of an anti-apoptotic protein Bcl-2 [38]. Furthermore, it was shown that overexpression of COX-2 promoted angiogenesis and tumor growth in endometrial carcinoma [39], and that COX-2 inhibitor in human prostate cancer cells inhibited their growth [40]. The probability of participation of COX-2 in the process of cell growth is supported by the fact that this enzyme is inducible by growth factors and mitogens [41]. Similarly to results of our investigations, up-regulation of COX-2 expression was observed e.g. in carcinomas of the lung, colon and breast [3], however, in uterine leiomyomas, Erol et al. [42] reported opposite observations.

IL- $1 \beta$ and TNF- $\alpha$ are the most prominent cytokines involved in iNOS stimulation. iNOS is one of three key enzymes generating nitric oxide (NO) which plays an important role in numerous physiological and pathophysiological conditions. It is well known that NO affects the expression of VEGF, angiogenesis, apoptosis, and prostaglandin production. The role of iNOS during tumor development is highly complex and presumably depends on the local concentration of iNOS within the tumor microenvironment [43]. To our best knowledge, our study is the first report on the localization and the immunoreactivity of iNOS in human uterine myomas. We found significantly higher immunoreactivity of iNOS in myoma tissue than in the control myometrium, which suggests an involvement of this enzyme in the pathogenesis of benign tumors. It seems to be consistent with other investigations that which reported that iNOS expression correlated with progression of human astrocytoma [44], human melanoma [45] and prostate cancer [46].

Expression of many cytokines and enzymes, such as TNF- $\alpha$, COX-2 and iNOS, which may control cell proliferation, cell survival or tumor development, was found to be regulated by a transcription factor-NF- $\kappa \mathrm{B}$ $[47,48]$. On the other hand NF- $\kappa$ B activity may be reciprocally regulated by the cytokines TNF- $\alpha$ or IL-1. They lead to the phosphorylation and degradation of $\mathrm{I} \kappa \mathrm{B}$, which results in the nuclear transfer of NF- $\kappa \mathrm{B}$. The classic form of NF- $\kappa \mathrm{B}$ is normally retained in cytoplasm through interactions with inhibitor proteins $\mathrm{I} \kappa \mathrm{B} \alpha$ and $\mathrm{I} \kappa \mathrm{B} \beta$ [4]. Such a condition probably occurred in our study, since in samples obtained from control uteri, which contained no myomas, and in samples with myomas the high immunoreactivity of $\mathrm{NF}-\kappa \mathrm{B}$ was restricted exclusively to the cytoplasmic compartment. No significant differences were observed in the number of stained nuclei between control groups and myomas groups. It might have been caused by the fact that there are five members of the mammalian NF- $\kappa \mathrm{B} /$ Rel family and the heterodimer composed of the p50 and 65 subunits is the classic form, and we examined only this type of NF- $\kappa$ B. However, studies of Cogswell et al. [49] indicated that only $\mathrm{p} 50, \mathrm{p} 52$, and c-Rel subunits were activated in human breast cancers without a corresponding consistent activation of the $\mathrm{p} 65$ subunit. The NF- $\kappa \mathrm{B}$ is generally considered active when it is in the nuclear localization rather than the cytoplasm. However, the overall expression level of this protein may also be related to its activity. Annunziata et al. [50] reported that an increase in cytoplasmic NF- $\kappa$ B transcription factor p50 was significantly associated with poorer patient survival. In myomas, cytoplasmic expression of NF- $\kappa$ B was highly elevated. Two observations have drawn our attention. For the first, independently whether data obtained from small or large myoma samples were compared, the levels of immunoreactivity in each age group of women were practically the same. However, samples obtained from women in reproductive age manifested higher cytoplasmic expression of NF- $\kappa \mathrm{B}$. Differences in the expression levels of the examined factors in tissues of women of different age may be dependent on the hormonal status. Our studies, for the first time, indicated the localization and expression level of NF- $\kappa \mathrm{B}$ in uterine myomas.

In conclusion, higher expression of the examined factors in uterine myomas in comparison to the control myometrium suggests involvement of these agents in the pathogenesis of uterine myomas.

\section{References}

1. Balkwill F. Tumor necrosis factor or tumor promoting factor? Cytokine Growth Factor Rev. 2002;13:135-141.

2. Elaraj DM, Weinreich DM, Varghese S et al. The role of interleukin 1 in growth and metastasis of human cancer xenografts. Clin Cancer Res. 2006;12:1088-1096.

3. Soslow RA, Dannenberg AJ, Rush D et al. COX-2 is expressed in human pulmonary, colonic, and mammary tumors. Cancer. 2000; 89:2637-2645.

4. Karin M, CaoY, Greten FR, Li ZW. NF- $\kappa$ B in cancer: from innocent bystander to major culprit. Nat Rev Cancer. 2002; 2:301-310.

5. Cao Y, Prescott SM. Many actions of cyclooxygenase-2 in cellular dynamics and in cancer. J Cell Physiol. 2002;190:279-286. 
6. Hayakawa T, Yamashita K, Ochuhi E et al. Cell-growth promoting activity of tissue inhibitor of metalloproteinase-2 (TIMP-2). J Cell Sci. 1994;107:2373-2379.

7. Ramsay B, Sooranna SR, Johnson MR. Nitric oxide synthase activities in human myometrium and villous trophoblast throughout pregnancy. Obstet Gynecol. 1996;87:249-253.

8. Tanaka YO, Nishida M, Tsunoda $\mathrm{H}$ et al. Smooth muscle tumors of uncertain malignant potential and leiomyosarcomas of the uterus: MR findings. J Magn Reson Imaging. 2004;20:998-1007.

9. Lee BS, Nowak RA. Human leiomyoma smooth muscle cells show increased expression of transforming growth factor- $\beta 3$ (TGF- $\beta 3$ ) and altered responses to the antiproliferative effects of TGF- $\beta$. J Clin Endocrinol MeTable 2001;86:913-920.

10. Lee MR, Kazer RR. Massive ascites after leuprolide acetate administration for the treatment of leiomyomas uteri. Fertil Steril. 1992;58:416-418.

11. Matsuo H, Maruo T, Samoto T. Increased expression of Bcl-2 protein in human uterine leiomyoma and its up-regulation by progesterone.J Clin Endocrinol MeTable 1997;82:293-299.

12. Senturk LM, Sozen I, Guteirrez L et al. Interleukin-8 production and interleukin-8 receptor expression in human myometrium and leiomyoma. Am J Obstet Gynecol. 2001;84:559-566 .

13. Maia H Jr, Pismental K, Casoy J et al. Aromatase expression in the eutopic endometrium of myomatosus uteri: the influence of the menstrual cycle and oral contreceptive use. Gynecol Endocrinol. 2007;23:320-324.

14. Poligone B, Baldwin AS. Positive and negative regulation of NF- $\kappa$ B by COX-2: roles of different prostaglandins. $J$ Biol Chem. 2001;276:38658-38664.

15. Danforth DN Jr, Sgagias MK. Tumor necrosis factor- $\alpha$ modulates oestradiol responsiveness of MCF-7 breast cancer cells in vitro. J Endocrinol. 1993;138:517-528.

16. Lin L, DeMartino GN, Greene WC. Cotranslational biogenesis of NF-kappaB p50 by the $26 \mathrm{~S}$ proteasome. Cell 1998;92:819-828.

17. Roberts AB, Flanders KC, Heine UI et al. Transforming growth factor-beta: multifunctional regulator of differentiation and development. Philos Trans R Soc Lond B Biol Sci. 1990;327:145-154.

18. Klimp AH, Hollema H, Kempinga C et al. Expression of cyclooxygenase-2 and inducible nitric oxide synthase in human ovarian tumors and tumor-associated macrophages. Cancer Res. 2001;61:7305-7309.

19. Ozel E, Peştereli HE, Simşek T et al. Expression of cyclooxygenase- 2 and inducible nitric oxide synthase in ovarian surface epithelial carcinomas: is there any correlation with angiogenesis or clinicopathologic parameters? Int J Gynecol Cancer. 2006;16:549-555.

20. Ali-Fehmi R, Semaan A, Sethi S et al. Molecular typing of epithelial ovarian carcinomas using inflammatory markers. Cancer. 2011;117:301-309.

21. Plewka A, Madej P, Plewka D et al. The TRAF2 and TRAF6 expression in myomas and myometrium of women in reproduction and perimenopausal age. Folia Histochem Cytobiol. 2010;48:407-416.

22. Cogswell PC, Kashatus DF, Keifer JA et al. NF- $\kappa$ B and I- $\kappa$ Ba are found in the mitochondria. Evidence for regulation of mitochondrial gene expression by NF- $\kappa \mathrm{B}$. J Biol Chem. 2003;278:2963-2968.

23. Medeiros R, Prediger RD, Passos GF et al. Connecting TNF- $\alpha$ signaling pathways to iNOS expression in a mouse model of Alzheimer's disease: relevance for the behavioral and synaptic deficits induced by amyloid beta protein. $\mathrm{J} \mathrm{Neu}$ rosci. 2007;27:5394-5404.

24. Hori M, Kita M, Torihashi S, et al. Upregulation of iNOS by COX-2 in muscularis resident macrophage of rat intestine stimulated with LPS. Am J Physiol Gastrointest Liver Physiol. 2001;280:G930-G938.

25. Nathan C, Xie QW. Regulation of biosynthesis of nitric oxide. J Biol Chem. 1994;269:13725-13728.

26. Di Iulio JL, Gude NM, King RG et al. Human placental and fetal membrane nitric oxide synthase activity before, during and after labour at term. Reprod Fertil Dev. 1995;7:1505-1508.

27. Madej P, Plewka A, Plewka D, et al. The aromatase expression in myomas and myometriums of women in reproduction and perimenopausal age. Folia Histochem. Cytobiol. 2009;47:497-504.

28. Shozu M, Murakami K, Inoue M. Aromatase and leiomyoma of the uterus. Semin Reprod Med. 2004;22:51-60.

29. Marsh EE, Bulub SE. Steroid hormones and leiomyomas. Obstet Gynecol Clin North Am. 2006;33:59-67.

30. Read NG, Rhodes PC. Techniques for image analysis. In: Immunocytochemistry. A practical approach. Ed. JE Beesley, IRL Press, Oxford Univ. Press 1993: 127-149.

31. Libby P, Warner SJ, Friedman GB. Interleukin 1: a mitogen for human vascular smooth muscle cells that induces the release of growth-inhibitory prostanoids. J Clin Invest. 1988;81:487-498.

32. Misior AM, Yan H, Pascual RM, Deshpande DA, Panettieri RA, Penn RB. Mitogenic effects of cytokines on smooth muscle are critically dependent on protein kinase $\mathrm{A}$ and are unmasked by steroids and cyclooxygenase inhibitors. Mol Pharmacol. 2008;73:566-574.

33. van Horssen R, Ten Hagen TL, Eggermont AM. TNF-alpha in cancer treatment: molecular insights, antitumor effects, and clinical utility. Oncologist. 2006;11:397-408.

34. Kurachi O, Matsuo H, Samoto T, et al. Tumor necrosis factor alpha expression in human uterine leiomyoma and its downregulation by progesterone. J Clin Endocrinol MeTable 2001;86:2275-2280.

35. Tergaonkar V. NF- $\kappa$ B pathway: A good signaling paradigm and therapeutic target. Int J Biochem Cell Biol. 2006; 38:1647-1653 .

36. Yu L, Wu WK, Li ZJ, Li HT, Wu YC, Cho CH. Prostaglan$\operatorname{din} \mathrm{E}(2)$ promotes cell proliferation via protein kinase $\mathrm{C} / \mathrm{ex}$ tracellular signal regulated kinase pathway-dependent induction of c-Myc expression in human esophageal squamous cell carcinoma cells. Int J Cancer. 2009;125:2540-2546.

37. Yamamoto M, Aoyagi M, Fukai N, Matsushima Y, Yamamoto $\mathrm{K}$. Increase in prostaglandin $\mathrm{E} 2$ production by interleukin-1 beta in arterial smooth muscle cells derived from patients with moyamoya disease. Circ Res. 1999; 85:912-930.

38. Tsujii M, Dubois RN. Alterations in cellular adhesion and apoptosis in epithelial cells overexpressing prostaglandin endoperoxide synthase 2. Cell. 1995; 83:493-501.

39. Li W, Xu RJ, Zhang HH, Jiang LH. Overexpression of cyclooxygenase- 2 correlates with tumor angiogenesis in endometrial carcinoma. Int J Gynecol Cancer. 2006;16:1673-1678 .

40. Ching TT, Wang DS, Song X, Rangnekar VM, Chen CS. The cyclooxygenase-2 inhibitor celecoxib induces apoptosis by blocking Akt activation in human prostate cancer cells independently of Bcl-2. J Biol Chem. 2000; 275:11397-11403.

41. Smith WL, DeWitt DL, Garavito RM. Cyclooxygenases: structural, cellular, and molecular biology. Annu Rev Biochem. 2000;69:145-182. 
42. Erol AYG., Aktepe F., Tokyol C et al. Relationship between mast cell subtypes and cyclooxygenase-2 expression in uterine leiomyomas. Pathol Res Pract. 2011;207:618-622.

43. Lechner M, Lirk P, Rieder J. Inducible nitric oxide synthase (iNOS) in tumor biology: the two sides of the same coin. Semin Cancer Biol. 2005;15:277-289.

44. Cobbs CS, Brenman JE, Aldape KD, Bredt DS, Israel MA. Expression of nitric oxide synthase in human central nervous system tumors. Cancer Res. 1995;55:727-730.

45. Massi D, De Nisi MC, Franchi A et al. Inducible nitric oxide synthase expression in melanoma: implications in lymphangiogenesis. Mod Pathol. 2009;22:21-30

46. Klotz T, Bloch W, Volberg C, Engelmann U, Addicks K. Selective expression of inducible nitric oxide synthase in human prostate carcinoma. Cancer. 1998;82:1897-1903.
47. Lim JW, Kim H, Kim KH. Nuclear factor-kappaB regulates cyclooxygenase-2 expression and cell proliferation in human gastric cancer cells. Lab Invest. 2001;81:349-360.

48. Ganster RW, Taylor BS, Shao L, Geller DA. Complex regulation of human inducible nitric oxide synthase gene transcription by Stat 1 and NF-kappa B. Proc Natl Acad Sci U S A. 2001;98:8638-8643.

49. Cogswell PC, Guttridge DC, Funkhouser WK, Baldwin AS Jr. Selective activation of NF-kappa B subunits in human breast cancer: potential roles for NF-kappa B2/p52 and for Bcl-3. Oncogene. 2000;19:1123-1131.

50. Annunziata CM, Stavnes HT, Kleinberg L et al. Nuclear factor kappa B transcription factors are coexpressed and convey a poor outcome in ovarian cancer. Cancer. 2010;116:3276-3284 .

Submitted: 13 February, 2012 Accepted after reviews: 12 March, 2013 